\title{
HSP or not HSP ... that is the question
}

\author{
David Cordiner, ${ }^{1}$ Clair A Evans, ${ }^{2}$ John Morrice ${ }^{1}$
}

${ }^{1}$ Department of Paediatrics, Victoria Hospital, Kirkcaldy, Fife, UK

${ }^{2}$ Department of Pathology, Yorkhill Hospital, Glasgow, UK

Correspondence to David Cordiner, davidcordiner@aol.com

\section{Summary}

The authors report on the case of a 10-year-old girl who presented with a vasculitic process primarily involving the skin, joints and kidneys, which was initially presumed to be a variant of Henoch-Schonlein purpura. When the disease process behaved in a more aggressive way than expected, with the rapid onset of acute renal failure, further investigation revealed the underlying diagnosis to be that of Wegener's granulomatosis.

\section{BACKGROUND}

This is a rare condition in the paediatric population, which may not be readily considered in a differential diagnosis. The non-specific signs and symptoms can pose a diagnostic challenge. It is an aggressive multi-system disorder, which has significant associated morbidity and mortality and requires timely treatment. Management of this condition requires input from multiple specialists and complex treatment strategies.

\section{CASE PRESENTATION}

The patient initially presented to the general practitioner (GP) with history of an itchy non-specific rash for several months. The GP managed this first with an oral steroid. This was effective in controlling the condition although it returned on cessation of treatment. A diagnosis of urticaria was made by the dermatology team who advised antihistamines.

Two months later the patient presented with swelling of both big toes and right ankle. At this time a rash was noted, mainly distributed over the distal limbs as in figures $1 \mathrm{~A}$ and $\mathrm{B}$. Also identified as being possibly relevant was a history of recurring mouth ulcers and an episode of hip joint inflammation in the preceding year that was diagnosed as a septic arthritis and managed accordingly. There was no family history of note.

Urinalysis was $3+$ positive for blood and $1+$ for protein. Blood pressure was within normal limits. Full blood count and electrolytes were normal. $C$ reactive protein (CRP) was 21. The possibility of a connective-tissue disorder was considered and further investigations sent for auto-antibody levels, including antineutrophil cytoplasmic antibody (ANCA). Henoch-Schonlein purpura (HSP) was considered to be the more likely diagnosis at this stage and she was discharged pending further results. She was subsequently reviewed a number of times over several weeks as an outpatient. The follow-up blood tests during this period are shown in table 1.

During this time her condition fluctuated. Urinalysis was persistently positive for blood while blood pressure was stable. Serial lab tests demonstrated an evolving trend with falling haemoglobin and rising creatinine, urea and CRP, the significance of which was not initially recognised. An antinuclear antibody test was negative and ANCA was still outstanding. Management continued according to guidelines for HSP.

When she attended for review, she had become systemically unwell with anorexia, weight loss, fever and a widespread erythematous rash. The blood tests on this date also marked the progression of her illness. She was referred to the regional tertiary referral hospital for further management under the care of the renal team. Treatments to control the immune mediated response are listed below. The trend of the laboratory investigations during this time is demonstrated in table 2 .

Table 1 Trend in full blood count parameters and C - reactive protein

\begin{tabular}{lllll}
\hline Date & 6 June & 17 June & 1 July & 7 July \\
\hline Hb & 13.5 & 12.9 & 10.6 & 8.4 \\
WCC & 13.6 & 10.2 & 12.5 & 12.4 \\
Plat & 295 & 360 & 338 & 370 \\
urea & 4.3 & 3.9 & 7.7 & 13.1 \\
creat & 66 & 64 & 111 & 231 \\
PV & 1.85 & 1.96 & & \\
CRP & 21 & 27 & 130 & 221 \\
\hline
\end{tabular}

$\mathrm{Hb}$, haemoglobin; WCC, white cell count; plat, platelets; creat, creatinine; PV, plasma viscosity; CRP, C reactive protein. 


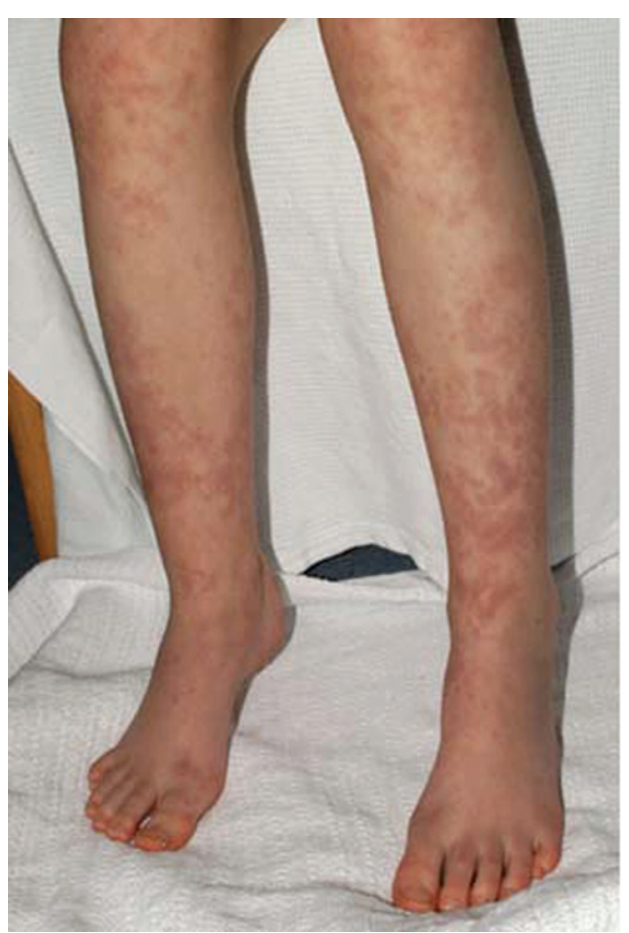

Figure 1 A and B Rash over anterior and posterior aspects of legs.

\section{INVESTIGATIONS}

The trends in basic haematology, biochemistry and CRP are demonstrated in the above section.

A renal biopsy was performed during the acute stage of the illness, which showed features consistent with active crescentic glomerulonephritis as in figure 2. Immunofluorescence on this sample was negative indicating that this process was not an IgA-mediated one as in HSP.

ANCA with specificity for proteinase 3 (PR3-ANCA) was positive. This in combination with the clinical findings allowed the diagnosis of Wegener's granulomatosis to be made.

Due to nose bleeds, she had an ear, nose and throat examination performed under general anaesthetic, which identified several bleeding points requiring cautery. A subsequent CT scan of her nasal cavity and sinuses was normal.

Given the diagnosis of Wegener's granulomatosis and its association with lesions in other body systems, ophthalmology and cardiology review with echo were carried out and noted to be satisfactory. CT scan of the chest was performed, which identified two asymptomatic nodular lesions in the right lung. One of these is indicated by an arrow in figure 3 .

\section{DIFFERENTIAL DIAGNOSIS}

HSP and other vasculitic processes.

\section{TREATMENT}

Initial management at the tertiary hospital consisted of induction of remission. This required pulses of methylprednisolone and the commencement of pulses of cyclophosphamide. Seven plasma exchanges were also carried out over a 2 -week period from day 7 of her tertiary hospital admission.

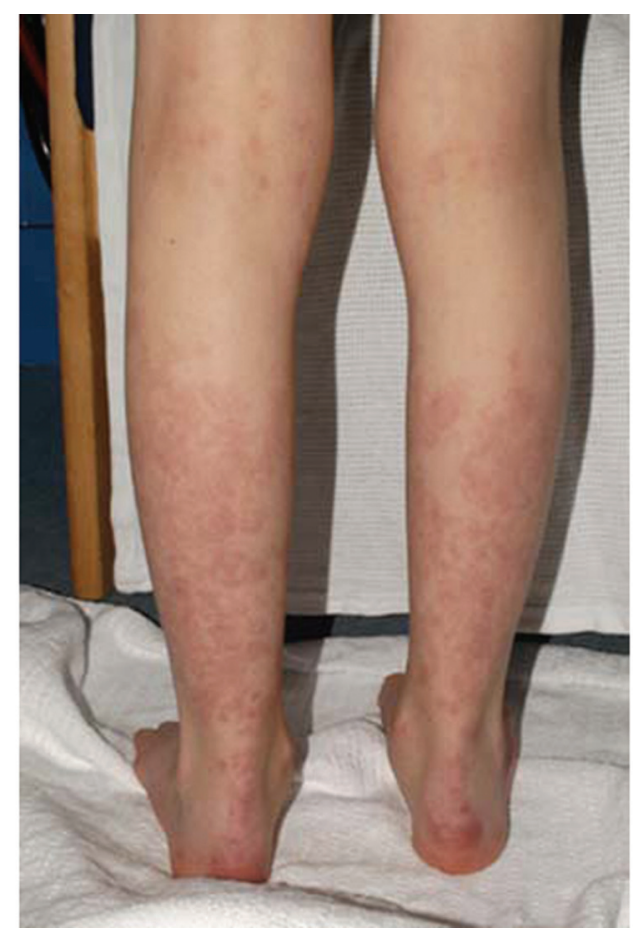

Oral antihypertensive treatments were required (furosemide and amlodipine). Aspirin was also added. She was discharged to continue with fortnightly pulses of cyclophosphamide.

As the frequency of cyclophosphamide infusions were reduced, there was evidence of an escalation in disease activity such that rituximab treatment was started. This is a new chimeric monoclonal antibody against the protein CD20 on the B cell surface, which disrupts the action of B cells and so may be used in auto-immune conditions. Two doses of this were administered 1 month apart, which helped to induce remission.

Maintenance of this remission has subsequently been achieved with mycophenolate mofetil, which is ongoing, and prednisolone, which has been weaned down to a dose of $5 \mathrm{mg} / 2.5 \mathrm{mg}$ on alternate days.

Other ongoing medication includes aspirin, amlodipine, enalapril, calcium supplements, alphacalcidol, erythropoietin (Epoetin beta) weekly injections and omeprazole.

\section{OUTCOME AND FOLLOW-UP}

Regular out-patient follow up is ongoing. The patient's clinical condition is currently stable. The prognosis is uncertain given the uncommon nature of this condition in the paediatric population and the potential side-effects of immunosuppressive treatment.

\section{DISCUSSION}

There is a range of known vasculitic conditions, which can be classified according to the size of vessel affected. The clinical signs associated with vasculitis affecting different vessel sizes are shown in figure 4. 


\section{BMJ Case Reports}

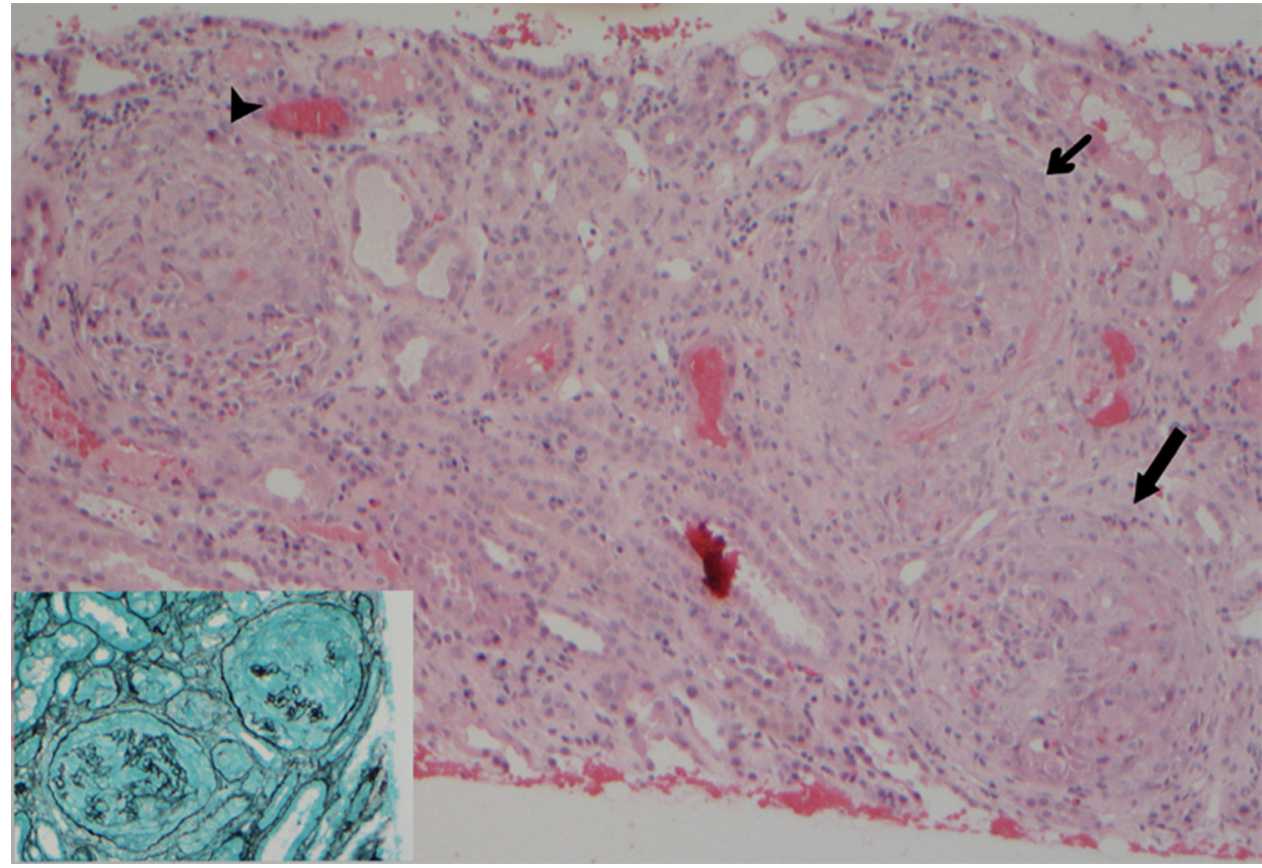

Figure 2 Renal biopsy (H\&E with silver stain, insert) $\times 200$ : The arrows highlight the three glomeruli in the H\&E photograph showing advanced crescentic glomerulonephritis. There is proliferation of parietal epithelial cells from Bowman's capsule together with infiltrating monocytes and macrophages. The silver stain insert highlights the partial obliteration of the glomerular tuft.

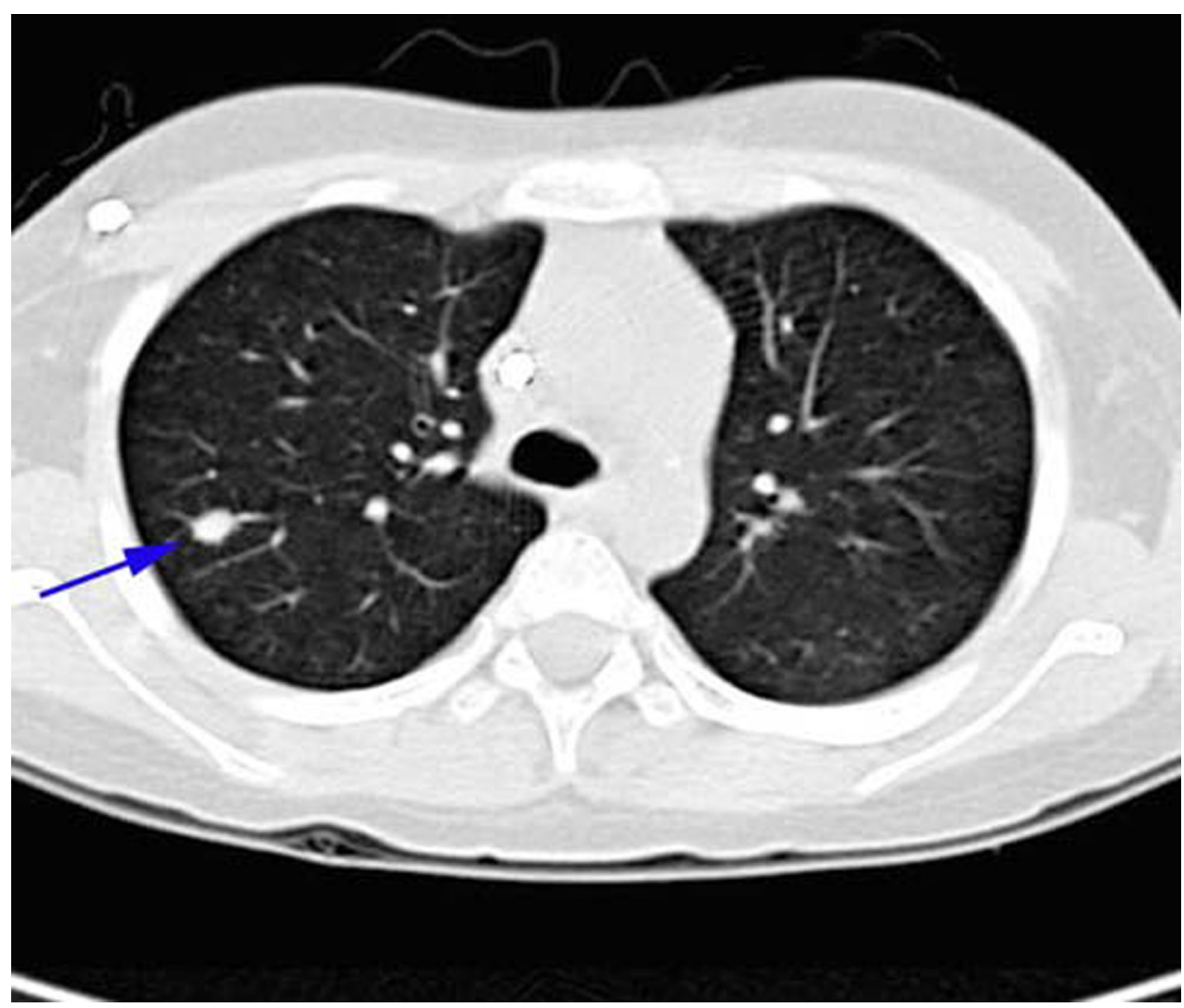

Figure 3 CT scan of chest showing asymptomatic nodular lesion in right lung as demonstrated by blue arrow. 
Table 2 Trend of the laboratory investigations upon treatment at tertiary referral hospital.

\begin{tabular}{|c|c|c|c|c|c|c|c|c|c|c|c|c|}
\hline $\begin{array}{r}\text { blo } \\
\text { transt }\end{array}$ & $\begin{array}{l}\text { od } \\
\text { usic }\end{array}$ & & $\begin{array}{l}\text { od } \\
\text { usiol }\end{array}$ & $\begin{array}{r}\mathrm{Pl} \\
\text { exc } \\
\text { st }\end{array}$ & $\begin{array}{l}\text { ma } \\
\text { ange } \\
\text { ted }\end{array}$ & & $\begin{array}{l}\text { od } \\
\text { fusior }\end{array}$ & & & & disch & arged \\
\hline July & 7/7 & $9 / 7$ & $11 / 7$ & $13 / 7$ & $15 / 7$ & $17 / 7$ & $19 / 7$ & $21 / 7$ & $23 / 7$ & $25 / 7$ & $27 / 7$ & $31 / 7$ \\
\hline $\mathrm{Hb}$ & 10.8 & 10.2 & 12.5 & 12.8 & 11.3 & 8.9 & 13.0 & 13.0 & 12.2 & 10.6 & 10.7 & 10.2 \\
\hline WCC & 12 & 14.5 & 19.5 & 12.3 & 24.5 & 12.7 & 10.7 & 15.2 & 13.7 & 10.2 & 12.0 & 21.4 \\
\hline Platelets & 310 & 434 & 429 & 525 & 437 & 220 & 212 & 232 & 193 & 177 & 151 & 164 \\
\hline Urea & 13.4 & 26.8 & 27 & 23.5 & 21.6 & 25.0 & 22.6 & 23.8 & 31.6 & 28.9 & 28.4 & 35.4 \\
\hline Creatinine & 230 & 273 & 244 & 240 & 212 & 240 & 274 & 283 & 307 & 221 & 196 & 221 \\
\hline CRP & 235 & 164 & 30 & 15 & 19 & 15 & $<7$ & $<7$ & $<7$ & $<7$ & $<7$ & 8 \\
\hline
\end{tabular}

HSP is a common type of small vessel vasculitis in the paediatric population. This is an IgA-mediated vasculitis often following on from an upper respiratory tract infection. ${ }^{1}$ It can affect multiple body systems and has a spectrum of severity, although in general it is a self-limiting process, which can be managed with symptom control and out-patient follow-up.

Far less common in this population is the condition Wegener's granulomatosis. This is also a multi-system vasculitic condition affecting small to medium vessels. It can affect any area of the body, including the upper and lower respiratory tract, kidneys, heart, joints, central nervous system and skin. ${ }^{1}$ The picture of organ involvement can vary widely between individuals. In two epidemiological population-based studies in England and Germany, the incidence rates for Wegener's granulomatosis were 10.6 and $6-12 /$ million/year, respectively. ${ }^{2}{ }^{3}$ The majority of cases were in those aged over 50 years.

In the paediatric population, Wegener's granulomatosis is extremely rare. ${ }^{4}$ For example, a tertiary referral children's hospital in Canada reported that only 25 cases had been managed there over a 21 -year period up to $2005 .{ }^{5}$

Criteria set out by the Paediatric Rheumatology European Society and European League Against Rheumatism for diagnosing Wegener's granulomatosis in children is shown in box 1.6

\section{Box 1}

Criteria for diagnosis of Wegener's granulomatosis in children as set out by the Paediatric Rheumatology European Society and European League Against Rheumatism. *If kidney biopsy is performed it characteristically shows necrotizing pauci-immune glomerulonephritis.

In trying to differentiate Wegener's granulomatosis from other vasculitic conditions, the ANCA test is particularly useful. The PR3-ANCA is highly sensitive and specific for Wegener's granulomatosis. ${ }^{7}$

The treatment of Wegener's granulomatosis generally involves immunosuppression. It will tend to fluctuate between periods of relapse and remission.

With the limited numbers of cases of Wegener's granulomatosis in the paediatric population, it remains uncertain what the long-term prognosis is. 


\section{Typical signs of systemic vasculitis Large Medium Small

\begin{tabular}{|l|l|}
\hline $\begin{array}{c}\text { Asymmetric blood } \\
\text { pressures } \\
\text { Absence of pulses } \\
\text { Bruits }\end{array}$ & $\begin{array}{l}\text { Cutaneous } \\
\text { nodules }\end{array}$ \\
Aortic dilatation & $\begin{array}{l}\text { Ulcers } \\
\text { Livedo reticularis } \\
\text { Digital gangrene } \\
\text { Mononeuritis } \\
\text { multiplex }\end{array}$ \\
& Microaneurysms \\
\hline
\end{tabular}

Purpura
Vesiculobullous lesions
Urticaria
Glomerulonephritis
Alveolar haemorrhage
Cutaneous extravascular
necrotizing granulomas
Splinter hemorrhages
Scleritis/episcleritis/uveitis

Figure 4 Clinical signs of vasculitis affecting different sized vessels.

\section{Learning points}

- Beware of deteriorating renal function in 'HSP' with haematuria.

- Consider causes of vasculitis less common in the paediatric population.

- Wegener's granulomatosis is a small vessel vasculitis that can present with features similar to more benign conditions like HSP.

- Be open-minded and ready to reconsider the diagnosis made initially if the disease does not behave as expected.

Competing interests None.

Patient consent Obtained.

\section{REFERENCES}

1. Savage $\mathrm{CO}$, Harper L, Cockwell P, et al. ABC of arterial and vascular disease: vasculitis. BMJ 2000;320:1325-8.

2. Watts RA, Gonzalez-Gay MA, Lane SE, et al. Geoepidemiology of systemic vasculitis: comparison of the incidence in two regions of Europe. Ann Rheum Dis 2001;60:170-2.

3. Reinhold-Keller E, Herlyn K, Wagner-Bastmeyer R, et al. Stable incidence of primary systemic vasculitides over five years: results from the German vasculitis register. Arthritis Rheum 2005;53:93-9.

4. Yalcindag A, Sundel R. Vasculitis in childhood. Curr Opin Rheumatol 2001:13:422-7.

5. Akikusa JD, Schneider R, Harvey EA, et al. Clinical features and outcome of pediatric Wegener's granulomatosis. Arthritis Rheum 2007:57:837-44.

6. Ozen S, Ruperto N, Dillon MJ, et al. EULAR/PReS endorsed consensus criteria for the classification of childhood vasculitides. Ann Rheum Dis 2006; 65:936-41.

7. King $T E$, Glassock RJ, Sheridan AM, et al. Clinical manifestations and diagnosis of Wegener's Granulomatosis and microscopic polyangitis. www.uptodate.com (accessed Aug 2008). 


\section{BMJ Case Reports}

This pdf has been created automatically from the final edited text and images.

Copyright 2010 BMJ Publishing Group. All rights reserved. For permission to reuse any of this content visit http://group.bmj.com/group/rights-licensing/permissions.

BMJ Case Report Fellows may re-use this article for personal use and teaching without any further permission.

Please cite this article as follows (you will need to access the article online to obtain the date of publication).

Cordiner D, Evans CA, Morrice J HSP or not HSP . . . that is the question. BMJ Case Reports 2010;10.1136/bcr.03.2010.2792, date of publication

Become a Fellow of BMJ Case Reports today and you can:

- Submit as many cases as you like

Enjoy fast sympathetic peer review and rapid publication of accepted articles

Access all the published articles

Re-use any of the published material for personal use and teaching without further permission

For information on Institutional Fellowships contact consortiasales@bmjgroup.com

Visit casereports.bmj.com for more articles like this and to become a Fellow 